\title{
The role of beauty for sustainability: a discussion on responsible consumption, aesthetics attitudes and product design
}

\author{
A. Marchand ${ }^{1}$, S. Walker ${ }^{1} \&$ P. De Coninck ${ }^{2}$ \\ ${ }^{1}$ Faculty of Environmental Design, University of Calgary, Canada \\ ${ }^{2}$ École de Design Industriel, Université de Montréal, Canada
}

\begin{abstract}
This paper explores the relationship between sustainability, and product aesthetic qualities and experience. It presents the result of an ongoing study notably looking at responsible consumption and the resulting visual culture. Initial insights are presented and thoughts that have emerged from this research experience are discussed. The link between eco-ethics, aesthetics, and the intrinsic and extrinsic properties of objects is briefly examined. The paper explores an 'aesthetic attitude' related to the ethical, spiritual and pragmatic facets of sustainability, and proposes the valorisation and celebration of beauty in these terms - as opposed to the surface "aestheticization of everyday life" that we are witnessing in contemporary society.

Keywords: product design, material culture, responsible consumers, ethics, aesthetics, aestheticization, beauty.
\end{abstract}

\section{Introduction}

Sustainability has fascinating implications for the aesthetic qualities of built environments, including the functional products that surround us, and for the way we experience them. Indeed, it is expected to affect how products look and are thought about, and to modify our response to a product's visual qualities. The paper provides some examples to illustrate these effects, and starts to explore how the project of sustainability challenges aesthetic conventions and social norms. Ongoing research into the significance of sustainability for product design, visual cultures and products aesthetics experience, is described. This study examines how some individuals promoting sustainability through their 
consumption habits, and more globally though their lifestyles, experience product aesthetics. Main aesthetic qualities that are meaningful to these identified responsible consumers, and that are derived from eco-ethics concerns are presented. This research leads us to reflections on sustainability, responsible consumption, and the dialogue between ethics and aesthetics. In this regard, the crucial role beauty could play in moving towards a more environmentally and socially viable world is discussed. The paper proposes to valorise and celebrate a type of beauty situated at the meeting of 'being good' and 'looking good'.

\section{Sustainable product design}

In the field of product development and manufacturing, sustainability involves reconsidering the way objects are thought about, developed, produced, distributed, used, reused, recycled, and disposed. Sustainable production and consumption mean ameliorating and modifying products and, more fundamentally, imagining new ways of living, and new cultural and social models. It is a demanding issue for product design and manufacturing because it is not simply about things, but about how we relate to things. In this context, product designers are invited to propose solutions that are, together with many other characteristics, more resource efficient, socially acceptable, and economically viable. Designers need to be capable of redesigning traditional products in these terms. More than this, they are asked to envision creative solutions where outcomes of traditional given consumption goods are achieved in a different and more sustainable way. This can notably be realized by responding to a particular need, the need for mobility for instance, through product-services-systems (Manzini and Vezzoli [1]). For design disciplines, sustainability has important implications in many areas, including the sphere of aesthetics. In terms of aesthetics, it implies changes in, firstly, the way the material world surrounding us looks and, secondly, in the way we aesthetically experience it.

\section{Aesthetics experience and product aesthetics}

Discussions about aesthetics may be confusing and inconsistent because, in common usage, the term refers to two different concepts (Crilly et al. [2]). Firstly, in the context of product aesthetics, 'aesthetics' or 'aesthetic qualities' usually relates to what the product presents to the senses. Secondly, in the context of aesthetics experience, the term refers to one particular aspect of cognitive response; the perception of how pleasing (or otherwise) is the process of regarding the product. The former is more directly concerned with the specific intrinsic qualities of the object, while the latter refers to the experience of these properties, an experience which may also be informed by the object's extrinsic properties. Extrinsic properties are those which are external to the artefact and which may notably be the result of various assumptions and a priori knowledge. These may be associated with characteristics such as the purpose of the object and its meaning, as well as the type of materials, form, colours, type of 
assembly, and, if known, various aspects of the production process and intentions behind the consumer product. For example, in recent years there have been various press revelations about the use of sweatshop labour in developing countries to produce products for Western markets. This extrinsic property of a particular object can, if known by potential purchasers or users, affect their aesthetic experience of it as a thing.

\section{Aesthetics and sustainability}

As mentioned earlier, sustainability in relationship to aesthetics involves two things: first, the modification of aesthetic qualities of the objects surrounding us, and secondly, changes in the representations of meaning attached to aesthetic qualities of our environment, including objects. It challenges many aesthetics conventions and social norms. For instance, from a sustainable perspective, our attachment to and use of the ubiquitous lawn in residential areas is problematic. Insistence on having a lawn is both highly wasteful and polluting when one considers the excessive amount of drinking water and energy consumed in maintaining one, as well as the common use of pesticides and fertilizers. Replacing lawn area with landscapes composed of native vegetations adapted to local climate would represent a more ecologically sound solution. Native vegetations do not require intensive care and maintenance as a lawn does, and constitute a far more amicable environment for insects and birds. Another example demonstrating how sustainability can challenge aesthetics and social conventions is the wearing of formal business apparel in the typical business setting. The air conditioning of office space has significant negative ecological impacts. Together with more efficient ventilation and air conditioning systems, the establishment of dress codes that are better suited to the climate and the season would be ecologically appropriate. At another level more directly related to the idea of changing the representation of meaning embodied in aesthetic qualities, the example of a varnished apple can be taken. The glossy apple is a widespread representation of the 'ideal' apple. However, in moving towards sustainability, the varnishing of apples could become associated with less environmentally sound practices, consequently modifying the concept of the 'ideal' apple.

\section{Ongoing research into material cultures and responsible consumption}

In an attempt to explore the potential implications of sustainability for product design, visual cultures and the way we experience product aesthetics, a study among identified responsible consumers has been undertaken. This study examines how some individuals promoting sustainability through their consumption habits, and more largely though their lifestyle choices, experience product aesthetics. Among other things, the research investigates the aesthetic qualities that are meaningful to these people. The study takes note of how ethics inform their aesthetical judgement, and how aesthetic qualities are used as landmarks to evaluate the ethical acceptability of products. 
More globally, the aim of this research is to gain insights into what might be termed a "responsible, sustainable material culture" by seeking to understand the choices and perspectives of self-identified responsible consumers with regard to functional products. As understood in this project, material culture refers to the user-product relationship and includes notions such as values, preferences and consumption choices, perception of meaning through object qualities, and aesthetic experience. The underlying premise of material culture is that manmade objects reflect the beliefs of the individuals who made, commissioned, purchased, or used them and, by extension, the beliefs of a particular community or society to which they belong or belonged (St-George [3]). Material culture studies examine aspects of the world of objects, including images, that people make, use and experience. According to Buchli [4], material culture studies refer to the study of the material world, but more exactly, to the study of the materiality of cultural life. Visual culture is here considered to be a part of material culture, more especially in how meaning is created and the relation between beliefs and construction of meaning through visual elements.

Eighteen individual interviews, each of one to three hours duration depending if respondents wanted to meet once of twice, have been conducted among eleven participants. Participants are people who consider themselves responsible consumers and who advocate, in various interpretations and at different levels, the notion of voluntary simplicity. During the semi-directed individual interviews, visual material and objects were used to stimulate the discussions. Images of various products and objects were presented to participants to open up and encourage the discussion of ideas and preconceptions attached to given visual qualities. In addition, visual data were generated by participants to further facilitate the exchanges. Prior to the interviews, respondents were invited to take photographs of objects that are aesthetically pleasing to them. Meetings of existing simple living groups where people primarily discuss the issue of responsible consumption were attended in order to gain further information about products in the context of responsible consumption. Twenty-one meetings were attended, totalling more than 40 hours of participant observation.

Briefly, voluntary simplicity (or simple living), which might be considered as a movement, is an attempt to achieve a better quality of life by minimizing the detrimental impacts of our ways of living on both the human and natural environments (Marchand and Walker [5]). Although this 'philosophy' is far from being a panacea for contemporary consumerism, many authors [6-10] see it as a direct response to consumer culture, and as a movement that holds lessons for a more viable, sustainable society.

Responsible consumption is here considered to be a process through which people make voluntary efforts to both reduce the amount of goods they consume and opt for more environmentally and socially sound solutions. The model proposed by Hansen and Schrader [11] is used here to define responsible, sustainable consumption:

1. Abstention from consumption; satisfying certain needs without the purchase and use, and in some cases even questioning the very need for, a given product; 
2. Reducing consumption;

3. Using ecologically and/or socially sound product variants, i.e., choosing product variants that are or are perceived to have greater environmental and social integrity; and

4. Using ecologically and/or socially sound substitutes, i.e., switching to products and/or services that are or are perceived to be consistent with sustainable practices

\section{Perception of meaning through Objects Visual Qualities}

In conducting the study among identified responsible consumers, the considerable influence of ethical concerns on the aesthetic experience of products has been frequently observed. The information these citizens retain about the ecological or ethical integrity of a particular product, as well as the suppositions they make in this regard, was found to have a significant impact on their aesthetic appreciation. In terms of assumptions, aesthetic qualities are used as a basis for evaluating the 'goodness' of the object; to form judgements about the acceptability of the product and the world that lies behind it. Certain aesthetic qualities or typologies are associated with accepted and desirable intentions and larger practices, others with environmentally and socially harmful ones.

For example, their critique of novelty for its own sake and its detrimental effects motivates a certain preference for objects presenting prototypical characteristics when acquiring new and highly mass produced products. Prototypicality here refers to the degree to which an object is representative of a category. Prototypes are usually defined as "[...] central representation of a category as possessing the average or modal value of attributes of that category" (Veryzer and Hutchison [12]). However, differences and diversity of expression are greatly valued as long as they are perceived as being meaningful, of aesthetic value and in-line with sustainable concerns - and not simply as novelty for its own sake or as an abusive marketing ploy.

Also, as they often feel that many contemporary consumer goods are overequipped, something which they find illustrative of a certain culture of excess, they shared a clear preference for objects with limited features. These are perceived as being longer-lasting as well as easier to maintain and repair. They also proved to be highly sensitive to the quantity of material that composes a product and tend to prefer objects minimizing the use of material.

Respondents highly appreciate products that they can easily understand in terms of constitution and function. Indeed, they esteem intelligible objects where, for example, the mechanism is apparent and/or accessible to the user - in opposition to products where the functional elements are in some way hidden. Being able to understand the functioning of an object gives them the feeling that they have control over the object, and that they can repair it if broken, or at least understand the malfunction. They further report enjoying using objects that 
allow them to feel that they are physically involved in achieving the task to be accomplished. For example, we have found that they value objects such as a manual peppermill or a manual coffee percolator.

Finally, participants valued natural and raw materials over composite materials which, as they pointed out, might or might not be recyclable. Preferences for such materials and finishes seem to be in line with a study showing that, in a different but related area, responsible consumers prefer food with strong and authentic tastes, such as dark chocolate over mild chocolate, and non-processed foods (Lauer [13]).

\section{Restoring the dialogue between ethics and aesthetics}

In Undoing Aesthetics, Welsch [14] discusses the relationship between aesthetics and ethics, and describes the term 'aesthetics' as being derived from the Greek term aisthesis. Aisthesis has a double meaning: perception and sensation. On the one hand, as perception, it "[...] addresses genuine sensuous qualities such as colours, sounds, tastes, and smells." On the other hand, as sensation, it follows an emotive perspective. The former may be understood as being linked to a more 'objective' response while the latter belongs to the more 'subjective' domain involved in the aesthetics judgement and notably comprises the space where the ethical reflection may lie. Welsch severely deplores the fact that perceiving has become autonomous whereas Eaton believes in "[...] a kind of merit in which being good and appearing (looking, sounding, tasting) good are integrated" (Eaton [15]). Welsch condemns the rupture between perception and sensation, both in academic discourse and day-to-day life, and calls for their reconciliation as a vital imperative.

The relationship between these two dimensions is important because their reconciliation allows us to envision a world where aesthetic experience and beauty are synonymous with, if not the source of, justice and vice-versa. Responsible consumption truly seems to constitute a privileged space for restoring this dialogue as it encourages an aesthetic reflection, or an aesthetic attitude, that is informed by environmental and socio-economic responsibilities. While it is clear that correct or truthful information about an object can affect the aesthetic experience of it, it is not clear to what extent an object's appearance may reveal this information [16]. There are obvious limits to how much an object may actually reveal about itself, but to some degree, objects still embody the intentions and purposes of their makers (Buchanan [17]). To a great extent, the essence of a product's aesthetic is a function of the system that produced it, and it follows that the aesthetics of most consumer products are the aesthetics of immoderate waste, and environmentally and socially damaging practices (Walker [18, 19]).

\section{Valuing and celebrating beauty against the aestheticization of everyday life}

According to Welsch, we are currently experiencing an "aesthetics boom" where "[m]ore and more elements of reality are being aesthetically mantled." Known 
as the aestheticization of everyday life, this phenomenon " $[\ldots]$ refers to the rapid flow of signs and images which saturate the fabric of everyday life in contemporary society" (Featherstone [20]). As a process of surface aestheticization or styling of the mundane, it lies in "[...] the embellishment and sensualization of everyday objects, environment and experiences" (Hancock [21]). It should be noted that, in this context 'aestheticization' refers to 'styling'.

Outside purely academic circles, the issue of aestheticization is also present and discussed. For instance, in a recent article published in The New York Times Magazine about product design and business strategy, the following question was asked: "Must even the most mundane household object rise up and join the tyranny of 'good' design?" (Walker [22]). Also, in Intramuros [23], a magazine dedicated to designers and design practice, the aestheticization of everyday life phenomenon was characterized and discussed under the terms "generalized invasion of aesthetic value" and "propaganda." The main points expressed were that "the democratization of beauty has become an ongoing concern" in which "everything is supposed to "look good" and where "everything and everybody has become beautiful." Although the phenomenon is applauded by some for "[...] offering both immense pleasure and rich resources for the construction of identity" (Duncun [24]), its economic purposes and foundations cannot be ignored (Welsch [14]). In turn, one could argue that it serves the interests of multi- and transnational corporations which tend, at the global scale, to reduce diversity of expressions through an unvarying 'corporate aesthetic' or 'style' notwithstanding cultures, people and places.

With regard to what has been described as the "tyranny of 'good' design" and the "generalized invasion of aesthetic value," some critiques can be formulated. In the first place, considering the lucrative aspect of these surface types of 'beauty' concerned with outward appearance and styling, it could be argued that the excessive "democratization of aesthetics" has resulted in an understanding of the concept of beauty as an object of consumption. Supporting a loss of meaning and encouraging today's saturated consumer culture, the excessive quest for 'beauty' that we are actually witnessing may actually undermine our relationship with objects, other people, and the bio-physical world. In fact, as Chabot [25] has said, "[t]he problem is not that beauty is too valorised, the problem rather lies in the growth of impoverished forms of beauty." Postrel [26] has suggested that sensory appeals are becoming ever more prominent in our culture and this is why, according to her, "[t]o maintain a healthy balance between substance and surface, we can no longer simply pretend that surfaces don't matter." Surface really does matter and has legitimate value. The idea here is not to reject our sensory nature, but to look for restoring the dialogue between surface and substance.

However, we believe that the valorisation and celebration of beauty - in the sense of being good and appearing good (looking, sounding, tasting) - has an unsuspected power against superficial styling and its detrimental effects. In fact, an aesthetic experience informed by eco-ethical concerns will not find pleasure through superficial, excessively commercial expressions, but rather only through genuine diversity, creativity and fairness. 


\section{Conclusions}

This paper has explored some aspects of the significance of sustainability for product aesthetic qualities and product aesthetic experiences. The distinction between these two concepts has been made. In the context of product aesthetics, aesthetic qualities refers more directly to what the product presents to the senses, while aesthetic experience concerns the cognitive response to those properties. This paper suggests that, in moving toward a more sustainable world, both our visual cultures and object visual qualities will be different. In this connection, to explore potential effects of sustainability on visual cultures, the initial results of an ongoing study on responsible consumption and material cultures has been presented. The study establishes the link between eco-ethics concerns and aesthetics appreciation. In addition, the initial results begin to outline some aesthetic qualities that are valorised and appreciated among those people who, through their consumption choices, and more largely in their daily life, work to incorporate some sustainability principles. Based on various assumptions, some typologies are often associated with more environmentally and socially acceptable practices. The study found that the interviewed responsible consumers show a strong preference for objects presenting prototypal characteristics when it is question of new and highly mass produced products, and for natural and raw material over composites. The study also noted a preference for functional products presenting limited features with minimal use of material. Respondents value objects that can be easily understood in terms of their constitution and operation, as well as products that allow them to be physically involved in realising the task they wish to accomplish. Based on some thoughts that have emerged from this research experience, the paper discussed the importance of restoring the dialogue between ethics and aesthetics. To this end, responsible consumption was considered, with some limits, as a privileged space to that allows for this, as it invites aesthetical reflections informed by eco-ethical concerns. Finally, the paper proposed to celebrate and valorise beauty against the surface aestheticization of everyday life, and for sustainability in and of itself.

\section{References}

[1] Manzini, E., Vezzoli, C., Product-Service Systems and Sustainability: Opportunities for Sustainable Solutions, UNEP: Paris, 2002.

[2] Crilly, N., Moultrie J., Clarkson, J.P., Seeing Things: Consumer Response to the Visual Domain in Product Design, Design Studies, 25 (6), pp. 547577, 2004.

[3] St-George, R.B., Material Life in America: 1600-1860, Northeastern UP: Boston, 1988.

[4] Buchli, V., Introduction, The Material Culture Reader, ed. V. Buchli, Berg: Oxford and New York, pp. 1-26, 2002.

[5] Marchand, A., Walker, S., Designing Alternatives, Sustainable Consumption, Lifestyles and 'Responsible Consumers', Proc. of the 
SCORE Workshop: Changes to Sustainable Consumption and Production, eds. M. Andersen \& A. Tukker, Copenhagen, 2006. Online. [http://www.score-network.org/score]

[6] Shaw, D., Newholm, T., Voluntary Simplicity and the Ethics of Consumption, Psychology and Marketing, 19 (2), pp. 167-185, 2002.

[7] Reisch, L.A., Scherhorn, G., Sustainable Consumption, The Current State of Economic Science, 2, pp. 657-690, 1999.

[8] De Graaf, J., Wann, D., Naylor, T.H., Affluenza: The All-Consuming Epidemic, Berrett-Koehler Publishers: San Francisco, 2001.

[9] Maniates, M., Confronting Consumption, eds. T. Princen, M. Maniates, K. Conca, The MIT Press: Cambridge (MA) and London, 2002.

[10] Etzioni, A., Voluntary Simplicity: Psychological Implications, Societal Consequences, Voluntary Simplicity: Responding to Consumer Culture, eds. D. Doherty \& A. Etzioni, Rowman and Littlefield Publishers: Lanham. pp. 1-25, 2003.

[11] Hansen, U., Schrader, U., A Modern Model of Consumption for a Sustainable Society, Journal of Consumer Policy, 20, pp. 443-488, 1997.

[12] Veryzer, R. W., Hutchison, J.W., The Influence of Unity and Prototypicality on Aesthetics Responses to New Product Design, Journal of Consumer Research, 24, pp. 374-394, 1998.

[13] Lauer, S., Les 'Alterconsommateurs' Contre-Attaquent: Les Français se Rebellent Contre la Consommation de Masse, Le Devoir, June 20th, A-1, 2004.

[14] Welsch, W., Undoing Aesthetics, Sage Publications: London, p. 62, 1997.

[15] Eaton, M., Merit, Aesthetic and Ethical, Oxford University Press: New York, p. 1, 2001.

[16] Elliott, J., Reconciling Eco-Ethics \& Aesthetics in Design, Design Philosophy Papers, 2, 2004. Online. [http://www.desphilosophy.com/dpp/home.html]

[17] Buchanan, R., Rhetoric, Humanism, and Design, Discovering Design, eds. R. Buchanan \& V. Margolin, The University of Chicago Press: Chicago, pp. 23-66, 1995.

[18] Walker, S., Conscientious Objects, Eternally Yours: Visions on Product Endurance, ed. E. van Hinte, 010 Publishers: Rotterdam, pp. 164-180, 1997.

[19] Walker, S., Unmasking the Object, Proc. of the European Academy of Design Conference, Bremen, 2005. Online. [http://ead06.hfkbremen.de/conference/tickets.html].

[20] Featherstone, M., Consumer Culture and Postmodernism, Sage Publications: London, p. 67, 1991.

[21] Hancock, P. (2002). Aestheticizing the World of Organization: Creating Beautiful Untrue Things, Tamara: Journal of Critical Postmodern Organization Science, 1 (1), pp. 91-105, 2002.

[22] Walker, R., The Way We Live Now, The New York Times Magazine, February, p. 42, 2004.

[23] Intramuros, Edito, Intramuros, 106, p. 13, 2003. 
380 Management of Natural Resources, Sustainable Development and Ecological Hazards

[24] Duncun, P., A Case for an Art Education of Everyday Aesthetic Experience, Studies in Art Education, 40 (4), pp. 298-311, p. 295, 1999.

[25] Chabot, M., Honorer le beau, Revue Notre-Dame, 100 (6), p. 16-28, p. 26, 2002.

[26] Postrel, V., The Substance of Style: How the Rise of Aesthetics Value is Remaking Commerce, Culture and Consciousness, Perennial: New York, 2003. 